\title{
Las elecciones presidenciales de 1970 en Colombia a través de la prensa. Un fraude nunca resuelto*
}

\section{Resumen}

Este artículo pretende hacer una reflexión sobre el fraude en las elecciones presidenciales de 1970 en Colombia. El proceso se estudia en tres momentos: el primero con relación a la campaña electoral de los cuatro candidatos, particularmente de los representantes de las coaliciones Frente Nacional, Misael Pastrana Borrero, y Alianza Nacional Popular (ANAPO), Gustavo Rojas Pinilla, en este punto se resalta la forma como estos candidatos hicieron uso de los periódicos para presentar su imagen. El segundo momento corresponde al conteo de los votos y a la intempestiva variación y presentación de los resultados electorales que dejó la sensación de fraude consumado, ello se analiza a partir de la forma como los periódicos regionales y de circulación nacional hicieron alusión al triunfo de uno y otro candidato. El tercero se relaciona con la legitimación de los resultados electorales, las denuncias de fraude por parte de los diversos actores sociales y las medidas del gobierno para solucionar el conflicto y garantizar la "democracia". En este estudio de historia política, la información obtenida en la prensa fue de gran relevancia porque permitió apreciar las confrontaciones políticas, las omisiones, las alianzas y las intencionalidades de las elites por conservar el poder. Las elecciones presidenciales de 1970 aunque significaron una apertura en el sistema democrático, son recordadas por los votantes como uno de los mayores fraudes en la historia electoral, puesto que se impuso al candidato del gobierno, lo que fue percibido por los seguidores de la ANAPO como una burla al sistema democrático.

Palabras clave: Colombia, elecciones, fraude, poder político, democracia, dictadura.

Referencia para citar este artículo: ACUÑA RODRÍGUEZ, Olga Yanet (2015). "Las elecciones presidenciales de 1970 en Colombia a través de la prensa. Un fraude nunca resuelto". En Anuario de Historia Regional y de las Fronteras. 20 (2). pp. 217-239.

Fecha de recepción: 14/10/2014

Fecha de aprobación: 03/12/2014

Olga Yanet Acuña Rodríguez: Doctora en Historia de la Universidad Pablo de Olavide. Licenciada en Ciencias Sociales y Magíster en Historia de la Universidad Pedagógica y Tecnológica de Colombia. Actualmente es docente de la Universidad Pedagógica y Tecnológica de Colombia. Correo electrónico: olgayanet@gmail.com.

\footnotetext{
* Artículo de reflexión que hace parte del proyecto de investigación "Elites, empresarios y movimientos sociales. Aproximaciones a un balance historiográfico", con financiación de la Dirección de Investigaciones de la Universidad Pedagógica y Tecnológica de Colombia.
} 


\title{
The 1970 presidential elections in Colombia through the media. An unsolved fraud ever
}

\begin{abstract}
This article intends to reflect on the fraud of the 1970 presidential elections in Colombia. These processes are studied in three moments: the first one is related to the electoral campaign of the 4 candidates; and, in particular, of the representatives from the alliances of the nationalist front, Misael Pastrana Borrero, and from Alianza Nacional Popular (Popular National Alliance), Gustavo Rojas Pinilla, emphasizing on the way these two candidates took advantage of the press to display their image; the second one corresponds to the tallying of votes and the untimely change and publishing of the electoral results which created the feeling of an accomplished fraud, analyzed from the way that the national and regional newspapers referred to the victory of one or the other candidate; the third one is related to the legitimation of the electoral results, which describes the fraud complaints by the different social stakeholders and the governmental measures to solve the conflict and ensure "democracy". In this political history study, the information obtained from the press was highly relevant because it allowed perceiving the political confrontations, the omissions, the alliances and the trends of the elites in order to preserve power. The 1970 presidential elections are remembered by voters as one of the major frauds in the history of Colombian elections, even though they signified the opening in the democratic system, because the government candidate was imposed, which was perceived by the Anapo supporters as a mock to the democratic system.
\end{abstract}

Keywords: Colombia, elections, fraud, political power, democracy, dictatorship.

\section{As eleições presidenciais de 1970 na Colômbia através da imprensa. Um fraude nunca resolvido}

\section{Resumo}

Este artigo pretende fazer uma reflexão sobre o fraude nas eleições presidenciais de 1970 na Colômbia. Estes processos são estudados em três momentos: o primeiro em relação à campanha eleitoral dos 4 candidatos; e particularmente dos representantes das coalizões frente nacionalista, Misael Pastrana Borrero, e da Aliança Nacional Popular, Gustavo Rojas Pinilla, destacando a forma como estes candidatos usaram os jornais para apresentar a sua imagem; o segundo momento corresponde à contagem dos votos e à intempestiva variação e apresentação dos resultados eleitorais que deixou a sensação de fraude consumado, analisado a partir da forma como os jornais regionais e de circulação nacional fizeram alusão ao triunfo de um e outro candidato; o terceiro aspecto tem a ver com a legitimação dos resultados eleitorais, em que se descrevem as denúncias de fraude por parte dos diversos atores sociais e as medidas do governo para solucionar o conflito e garantir a "democracia". Neste estudo de história política, a informação obtida na imprensa foi de grande relevância porque permitiu apreciar as confrontações políticas, as omissões, as alianças e as intencionalidades das elites por conservar o poder. As eleições presidenciais de 1970, mesmo significando uma abertura no sistema democrático, ficaram na memória dos eleitores como um dos maiores fraudes na história eleitoral, dado que foi imposto o candidato do governo, o qual foi percebido pelos seguidores da Anapo como uma falta com o sistema democrático.

Palavras-chave: Colômbia, eleições, fraudel, o poder político, a democracia, ditadura. 


\section{El proceso electoral visto a través de la prensa}

El papel de los medios de comunicación ha sido de gran relevancia para crear identidad política, para permitir a las diversas facciones políticas tener un espacio público e incidir en el potencial electoral; de esta manera ha contribuido en la formación de una perspectiva democrática ${ }^{1}$. La prensa cumplió el rol de informar, agitar y afianzar identidades partidistas, se convirtió en un actor político que influyó considerablemente en la lucha electoral, puesto que contribuyó a consolidar la maquinaria y a presentar la imagen de los candidatos para intentar incidir en el electorado. En los comicios de 1970 la prensa fue un medio indispensable en la campaña, ya que difundió ideas y contradicciones, generando agitación electoral en defensa o en oposición al gobierno, según el caso. Como lo señala Silvia González, respecto de México, la prensa es fundamental para comprender los escenarios del proceso electoral, a través de los cuales se pueden apreciar los discursos, las tendencias político-ideológicas y el papel de estas publicaciones en el juego político ${ }^{2}$. Indudablemente, este medio de comunicación contribuyó a captar la opinión y atraer el interés de la sociedad civil, algo que se pudo apreciar en la relación entre acuerdos y disidencias con el gobierno ${ }^{3}$.

En el caso de las elecciones presidenciales de 1970 en Colombia, las versiones son diversas, pero en la memoria de la mayoría de los colombianos permanece el recuerdo del fraude que le otorgó a Misael Pastrana Borrero la presidencia; las incógnitas sobre el conteo de los votos y la consolidación de los resultados oficiales generaron en su momento fuertes polémicas, manifestaciones y acciones de protesta de los electores inconformes. Además, subsiste una brecha entre aquello que recuerdan los diversos actores y la legalidad de los registros. Antes de adentrarnos en el tema es importante ver de qué manera la historiografía se ha ocupado de la temática y cuáles han sido los principales debates y vacíos sobre las elecciones presidenciales de 1970 en Colombia.

La historiografía electoral en Colombia, aunque ha avanzado considerablemente en analizar la participación de los diversos actores sociales, las estrategias de poder y los mecanismos de presión a los electores, ha dejado fuertes vacíos sobre las redes, el papel de los actores sociales y los intereses que se mueven alrededor de los resultados electorales con los que se pretende legitimar el poder, como lo plantean Eduardo Posada y David Bushnell $1^{4}$. Para bien o para mal, las elecciones siguen siendo el medio que legitima el poder de las instituciones del Estado; sin embargo, para obtener el triunfo es necesario poner en juego diversos mecanismos de poder, entre los que se destacan el fraude, la violencia y el clientelismo ${ }^{5}$, que a la vez son prácticas consustanciales al

\footnotetext{
${ }^{1}$ GANTÚS, Fausta y SALMERÓN, Alicia, Prensa y Elecciones formas de hacer política en el México del siglo XIX, México, Instituto Mora, 2014.

${ }^{2}$ GONZÁlEZ MARÍN, Silvia, Prensa y Poder Político, la elección presidencial de 1940 en la prensa mexicana, México, Editorial Siglo XXI, 2010, pp. 9-10.

${ }^{3}$ GANTÚS, Fausta, Caricatura y poder politico. Caricatura, censura y represión en la ciudad de México, 1876-1888, México, El Colegio de México, 2009, p. 15.

${ }^{4}$ BUSHNELL, David, "Las elecciones en Colombia: S. XIX para bien o para mal, las elecciones han sido una característica nacional”, en Revista Credencial de Historia, No. 50, Bogotá, 1994.

${ }^{5}$ ACUÑA RODRÍGUEZ, Olga Yanet, Elecciones y Construcción de ciudadanía en Boyacá, durante la
} 
sistema democrático y han acompañado el desarrollo de las elecciones. En el evento de 1970, los actores sociales, colectivamente recuerdan cómo se transformaron los resultados electorales en favor del candidato oficialista.

César Ayala se refiere a los usos y abusos de la memoria con relación a las elecciones presidenciales de 1970 en Colombia; aunque su objetivo central es estudiar el origen y la proyección de la Alianza Nacional Popular (ANAPO) como movimiento político alternativo, hace un amplio seguimiento a la campaña electoral de 1970 y a sus resultados, destaca que efectivamente el papel de la ANAPO con la implementación de otros rituales en la forma de hacer política fue lo que convocó a los sectores populares $^{6}$. Dicho trabajo constituye una base sustancial para el desarrollo de este texto, aunque nuestro estudio se centra en analizar la prensa como actor político en la configuración del proceso electoral y en la configuración de la imagen de los candidatos y opositores.

Habían transcurrido solamente 20 años de una de las luchas políticas más violentas: las elecciones presidenciales de 1949, en las que el conservatismo imponía la candidatura de Laureano Gómez, para dar continuidad a la hegemonía ${ }^{7}$. La situación política afectaba más a los sectores populares, dado que los líderes y dirigentes políticos, liberales y conservadores, con mucha regularidad negociaban las curules, el reparto burocrático de las instituciones y hasta el triunfo. Precisamente, el Frente Nacional, iniciado en 1958, fue el resultado de un acuerdo político para poner fin al conflicto bipartidista; acuerdo que, en últimas, integró las elites liberales y conservadoras, pero abrió una honda brecha con los sectores populares, que esperaban cambios profundos que les permitieran mejorar sus condiciones de vida.

Pero, ¡oh sorpresa!, los dirigentes políticos no contaron con que los diversos sectores sociales querían un cambio, que se habían apropiado de su papel como ciudadanos para explorar opciones políticas que garantizaran sus derechos; de este modo sus intereses empezaron a tomar sentido más allá de la tradicional lucha bipartidista, aunque estas pretensiones entraban en contradicción con el oficialismo político, hecho que contribuyó al debilitamiento del Frente Nacional ${ }^{8}$. Este acuerdo electoral tal vez nunca haya sido entendido por los campesinos y sectores populares, porque para ellos no era fácil unirse a su enemigo político y trabajar en conjunto, mientras crecían el hambre, las necesidades y la pobreza.

La debilidad del acuerdo bipartidista se pudo apreciar a través del inconformismo de los sectores populares y del surgimiento de cuatro candidatos para la elección presidencial de 1970 -la cuarta y última del Frente Nacional-, todos de tendencia

República Liberal 1930-1946, Tunja, Universidad Pedagógica y Tecnológica de Colombia, 2010.

${ }^{6}$ AYALA DIAGO, César Augusto, El populismo atrapado, la memoria y el miedo, el caso de las elecciones de 1970, Medellín, la Carreta Histórica, 2006.

${ }^{7}$ ACUÑA RODRÍGUEZ, Olga Yanet, "Elecciones presidenciales de 1949 en Boyacá", en GUERRERO, Javier y ACUÑA, Olga (Eds.), Para reescribir el Siglo XX, Medellín, La Carreta, 2011.

${ }^{8}$ Acuerdo político entre las elites liberales y conservadoras para alternarse el poder por periodos de cuatro años. 
conservadora, dado que por la alternancia pactada le correspondía el turno al Partido Conservador. En primer lugar, Misael Pastrana Borrero, en representación del oficialismo frente-nacionalista, era el candidato de las elites liberales y conservadoras unidas. En segundo lugar, Gustavo Rojas Pinilla, de ascendencia conservadora y con una perspectiva política nacionalista, representaba a la Alianza Nacional Popular, nuevo partido político fundado por disidentes del liberalismo, conservatismo y por sectores populares y de izquierda, nostálgicos de la dictadura del exgeneral Rojas. En tercer lugar, Belisario Betancourt, conservador del departamento de Antioquia, crítico del Frente Nacional y con una propuesta de gobierno social-cristiano. Y finalmente, Evaristo Sourdís, conservador de la Costa Atlántica, mostraba sentido social, su programa de gobierno se enfocó en reivindicar la autonomía de las regiones.

Los cuatro candidatos presidenciales estuvieron atentos al fervor de las masas; recorrieron el país, pronunciaron discursos, organizaron concentraciones, reuniones, asambleas y demás actividades electorales. De esta manera, se planteó una apertura democrática para que los electores seleccionaran al presidente y su propuesta de gobierno, esto debilitó la tradicional relación bipartidista, aunque en la campaña electoral el oficialismo contó con toda la maquinaria, con los medios de comunicación y con las constantes intervenciones del presidente Carlos Lleras Restrepo en favor del régimen de coalición. Por su parte, los sectores populares que fueron seguidores de Gaitán y que no habían encontrado un proyecto político que los articulara, les devolviera la llamada paz social y los hiciera sentir parte de un proyecto de construcción de nación y de integración social y económica ${ }^{9}$, vieron en la ANAPO la esperanza de cambio, por ser una propuesta independiente al tradicionalismo y a la prolongación del régimen bipartidista; en ello contribuyó la Iglesia católica.

Durante la campaña electoral, el uso de la memoria fue crucial; cada candidato acudió a diversas estrategias para llegar a los electores; el despliegue se hizo a través de los grandes medios de comunicación, de correrías, manifestaciones, desfiles y discursos; de igual forma, por medio de carteles, afiches e insignias a nombre de los candidatos. Gustavo Rojas Pinilla y Misael Pastrana Borrero desplegaron mayor actividad; el primero, por ser expresidente y hablar a nombre de una coalición entre izquierdas, disidentes de derecha e Iglesia católica y, sobre todo, a nombre del pueblo; el segundo, por representar el oficialismo y los intereses de las elites. Una de las características de esta campaña fue hacer alusión a las multitudes que seguían al candidato, lo que daba la sensación de mayorías, de fuerza y respaldo; así, todos los medios publicaron fotos de los aspirantes a presidencia y las manifestaciones donde se apreciaban las multitudes.

Los comicios del 19 de abril de 1970 tuvieron por objeto elegir tanto al presidente de la República como a los miembros de las diversas corporaciones públicas, hecho que se daba por primera vez en el país; además, se elegiría Cámara de Representantes para un periodo de cuatro años, también por primera vez; sumado a esto, después de un lapso de doce años, los Concejos municipales y las Asambleas departamentales volvían a

${ }^{9}$ AYALA DIAGO, César Augusto, Op. cit., p. 23. 
Las elecciones presidenciales de 1970 en Colombia a través de la prensa. Un fraude...

integrarse mediante el juego de las mayorías partidistas sin el límite o equilibrio de la paridad establecida por el pacto del Frente Nacional.

A continuación se hace alusión a las actividades preelectorales realizadas por los cuatro candidatos:

\section{Evaristo Sourdís}

Sourdís defendió la provincia y planteó su fortalecimiento; su candidatura estuvo apoyada por los periódicos El Siglo, de Bogotá, y El Heraldo, de Barranquilla, que en sus primeras páginas publicaron imágenes de las manifestaciones en adhesión al candidato, con multitudes que portaban pancartas y banderas azules ${ }^{10}$; de igual manera, se destacó la adhesión de líderes políticos de la Costa Atlántica. Su gira se orientó a visitar las localidades de Boyacá, específicamente la población de Moniquirá ${ }^{11}$ y, posteriormente, Tolima ${ }^{12}$.

El Siglo y El Heraldo fueron críticos con el gobierno de coalición y se pronunciaron en contra de la parcialidad en el uso de los medios de comunicación y de la intervención frecuente del presidente en la campaña electoral a favor de la candidatura de Pastrana, a la que llamaban la candidatura de la imposición ${ }^{13}$; precisamente, El Siglo cuestionó en un reportaje la labor de Lleras Restrepo y su campaña proselitista en la localidad de Kennedy de Bogotá, con niños y padres de familia ${ }^{14}$. De igual forma, El Heraldo hizo seguimiento a la actividad electoral de Sourdís en la costa, destacando las adhesiones y manifestaciones. Durante los días previos a las elecciones, estos diarios incrementaron la publicidad y las críticas contra la candidatura de Pastrana, que consideraban su antagónico, o simplemente hicieron alusión a cómo mejorar las condiciones de vida y sobre todo garantizar la pureza del sufragio. En una de sus intervenciones, Sourdís habló de la libertad del sufragio y de la necesidad de fortalecer los procesos electorales, asimismo, cuestionó que los medios publicitarios del Estado se pusieran al servicio solamente del "candidato de la imposición"15.

\section{Belisario Betancur}

Belisario Betancur fue considerado un líder joven que buscaba un espacio para escalar políticamente. El seguimiento a las actividades de este candidato fue realizado, principalmente, por el periódico La Patria, de Manizales ${ }^{16}$. Betancur hizo fuertes

\footnotetext{
${ }^{10}$ El Siglo, Bogotá, 1 de marzo de 1970; El Siglo, Bogotá, 2 de marzo de 1970; El Siglo, Bogotá, 3 de marzo de 1970; El Heraldo, Barranquilla, 2 de abril de 1970; El Heraldo, Barranquilla, 9 de abril de 1970.

${ }^{11}$ El Siglo, 6 de marzo de 1970; El Siglo, Bogotá, 8 de marzo de 1970; El Siglo, 9 de marzo de 1970.

${ }^{12}$ El Siglo, 19 de marzo de 1970.

13 "La candidatura de la imposición menospreciar a los dos partidos", en El Heraldo, Barranquilla, 10 de abril de 1970 .

${ }^{14}$ El Siglo, 27 de marzo de 1970.

15 "Mi candidatura es una alternativa de honestidad y libertad: Sourdís", en El Siglo, 12 de abril de 1970.

${ }^{16}$ La Patria, Manizales, 2, 3, 4 de abril de 1970; La Patria, Manizales, 4 de abril de 1970, este titular se refirió a la manifestación de Betancur en Antioquia; "Sourdís en San Marcos”, El Siglo, 10 de abril de 1970.
} 
críticas al oficialismo y al Frente Nacional. El 10 de abril se refirió al fracaso de la manifestación pastranista realizada en Neiva, consideraba que había sido una farsa y que evidenciaba la poca fuerza de ese candidato, al que calificaba de ser resultado de una imposición y no de la libertad del ciudadano ${ }^{17}$. Destacó la frecuente intervención del presidente Lleras Restrepo en la campaña, especialmente en las correrías por los barrios humildes, la inauguración de obras y el llamado directo a los electores a emitir su voto por el candidato oficial del Frente Nacional, Misael Pastrana. A su vez, esto suscitó reacciones de los diversos sectores, que se pronunciaron en contra de la parcialidad del presidente ${ }^{18}$. Igualmente, hubo fuertes denuncias de corrupción sobre la financiación de la campaña electoral; se hizo alusión a los descuentos de diez pesos, por nómina, efectuados a los funcionarios públicos en pro de la campaña de Misael Pastrana. En la denuncia presentada se retomaron datos de la Secretaría de Tránsito, pero se dejó la sensación de que en otras oficinas el tratamiento había sido similar ${ }^{19}$.

Con frecuencia, en La Patria, diario de Manizales, aparecían imágenes como la que se reproduce a continuación, en la cual de forma pintoresca se representa a los candidatos, lo que permite apreciar una polarización de sus pretensiones electorales y un debilitamiento del Frente Nacional.

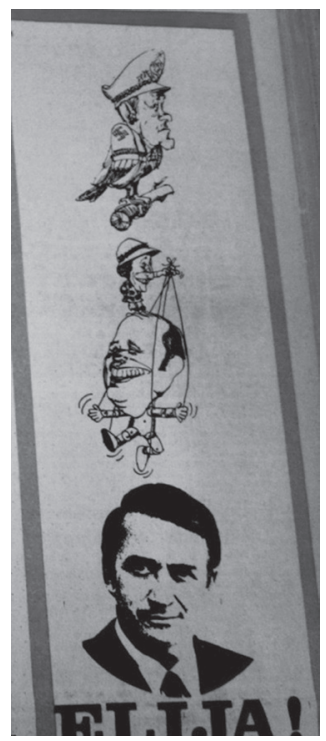

Fuente: La Patria, 10 de abril de 1970

\footnotetext{
17 "Imposición y dictadura: gobierno liberal enérgico llamado del caudillo para derrotar al sistema", en $L a$ Patria, 12 de abril de 1970; "Contra la dictadura y la imposición, Belisario es la solución”, en La Patria, Manizales, 13 de abril de 1970.

${ }^{18}$ Archivo General de la Nación, (AGN), Fondo Despacho del Sr. Presidente, secretaría privada, partidos políticos, correspondencia, 1970, caja No. 109, carpeta 1, Oficio enviado por Simón Viatella, de Cali, reseleccionado el 21 de marzo.

${ }^{19}$ AGN, despacho del Sr. Presidente, secretaría privada, partidos políticos, correspondencia, 1970, caja No. 109, carpeta 1, oficio de 27 de enero de 1970, procedente de la candidatura Betancur, sede Bogotá, firmado por Silvio Cancelada; dirigido a Mario Aramburo, Procurador General de la nación.
} 
En orden descendente aparecen los candidatos presidenciales: primero, Rojas Pinilla con el kepis de dictador y con cuerpo de ave, en representación de la figura del pájaro, es decir, de los asesinos que operaban en el Valle del Cauca en los años cincuenta y que coincidieron con el gobierno del general; enseguida, aparece Misael Pastrana Borrero, como un títere manejado por un representante de las elites políticas - puede ser el ospinismo-; posteriormente aparece la imagen de Belisario Betancur, que sería, según el caricaturista, el único que cumplía con los requisitos de un buen candidato y por quien se debía sufragar. De esta manera se representó la política colombiana en forma jocosa y que recoge ciertas expresiones colectivas sobre el papel de sus líderes.

\section{Gustavo Rojas Pinilla}

Este candidato inscribió su candidatura a nombre de la Alianza Nacional Popular, que pretendía convertirse en una verdadera coalición popular, sin distinción política y con un sentido social. La ANAPO organizó la campaña en el ámbito nacional y conformó comandos departamentales, municipales y veredales, lo que contribuyó a que su propuesta se convirtiera en un movimiento nacional y llegara hasta los lugares más apartados del país ${ }^{20}$. En este movimiento participaron disidentes liberales, conservadores y de otras tendencias políticas, que tuvieran una proyección cristiana y un proyecto nacionalista. El diario El Espectador reconocía: "La única organización que se extiende sobre todo el territorio nacional es la anapista", dado que mantenía una red organizada e intercomunicada en todas las regiones del país ${ }^{21}$.

Tanto el programa de gobierno de la ANAPO como la articulación de líderes políticos liberales y conservadores ofrecían una visión de cambio que era atractiva para los diversos sectores sociales. Para las masas, el sentido social de la propuesta de Rojas superó el interés por el tradicional bipartidismo. En ese momento, en la lucha electoral primaban las necesidades colectivas; así cobró sentido la pretensión de consolidar un gobierno legítimamente popular contrapuesto a las oligarquías.

Como parte del programa de gobierno presentado a través de su intervención por televisión, Rojas Pinilla propuso: rebajar el costo de vida, que se había incrementado durante los doce años de permanencia del Frente Nacional; nacionalizar el transporte y otros elementos de consumo; crear empleo; brindar educación totalmente gratuita, en escuelas, colegios y universidades, al igual que los servicios médicos, hospitalarios y el suministro de drogas; mantener una política de cordialidad con el Frente Nacional y, en general, con los demás partidos y grupos políticos. A su vez, hizo alusión a una rebaja tributaria -lo que sin lugar a dudas despertaba el interés de los sectores populares ${ }^{22}$, a la deuda pública, al presupuesto, a las carreteras y a la devaluación de la moneda ${ }^{23}$.

\footnotetext{
${ }^{20}$ AYALA DIAGO, César Augusto, Op. cit., p. p. 125.

21 "La contribución de Bogotá a la victoria", en El Espectador, Bogotá, 2 de marzo de 1970.

${ }^{22}$ El Espectador, 6 de marzo de 1970.

23 “Hernán Galindo habla Rojas", en El Espectador, 10 de abril de 1970.
} 
El diario El Tiempo realizó fuertes críticas a la intervención del expresidente, se refirió a él como el exdictador y señaló que sus planteamientos estaban llenos de cinismo, demagogia y manipulación al pueblo. También se dijo: el que "[...] ahora viene a presentarse como el salvador de la República", antaño con sus falencias en política económica generó una fuerte inflación ${ }^{24}$.

Como parte de la organización de la campaña, Rojas Pinilla realizó visitas a diversas localidades del país, especialmente las más apartadas, a las que posiblemente ningún dirigente político se había acercado para conocer y escuchar sus necesidades en forma directa y multitudinaria. Del mismo modo, la ANAPO desarrolló programas y actividades culturales en los barrios y localidades, que le permitían estar en permanente contacto con los electores y conocer de cerca sus necesidades. Los periódicos hicieron alusión a la manifestación de rojistas, realizada en el Valle del Cauca el 21 de febrero de 1970, en la que centenares de simpatizantes salieron a las calles en señal de apoyo a Rojas Pinilla, a María Eugenia y a la ANAPO. Esta manifestación fue presidida por Rojas Pinilla y los senadores Ignacio Vives Echeverría y José Ignacio Giraldo, además, fue considerada una demostración de poderío político y humano; se inició con un desfile automotor que resultó novedoso, toda una estrategia para convocar al electorado, hubo aproximadamente cien mil asistentes ${ }^{25}$. Lo innovador de esta forma de hacer política está en los desfiles automovilísticos y en la participación de caudillos de la ANAPO que tanto en la oratoria como en el contenido discursivo atraían la Atención de las masas.

Las manifestaciones de la campaña Rojas se caracterizaron por ser multitudinarias, como la que se realizó el 6 de abril en Bogotá, sin embargo, pocos periódicos les dedicaron espacio; las alusiones a la campaña del líder anapista se encuentran en las páginas internas y en muchas ocasiones en pequeños recuadros. Pese a lo anterior, la mejor forma de oposición era hablar de "El dictador". El recuerdo que tienen las elites sobre el gobierno de Rojas Pinilla es la imagen de dictador, capaz de censurar los medios de comunicación, de perseguir al adversario y despilfarrar el erario por falta de conocimiento en economía. Contradictoriamente, para la mayoría de los habitantes la imagen de Rojas es la de un héroe que logró bajar el costo de vida y mediar la situación de orden público.

\section{Misael Pastrana Borrero}

Líder conservador, representante de la coalición política liberal-conservadora que contribuyó al derrocamiento del gobierno militar de Gustavo Rojas Pinilla en 1958. Aunque no tenía propuestas concretas de gobierno, se escudó en las obras desarrolladas durante los gobiernos del Frente Nacional, en la invitación del presidente y de los principales líderes políticos del liberalismo y el conservatismo, así como en la intensa campaña adelantada a través de la prensa y la televisión, que hicieron las elites políticas.

${ }^{24}$ El Tiempo, Bogotá, 7 de marzo de 1970; "Si Rojas gana, desaparece la Constitución Nacional", en El Colombiano, 13 de abril de 1970.

${ }^{25}$ El Espectador, 1 de marzo de 1970. 
Los periódicos El Tiempo, El Espectador, El Colombiano, Vanguardia Liberal (de Bucaramanga) y El País (de Cali), junto con la revista Cromos, destacaron las actividades realizadas por el candidato Pastrana; diariamente publicaban fotos de sus manifestaciones, visitas y correrías a diversos lugares. A comienzos de marzo, estos medios hicieron seguimiento de la visita de Pastrana a la Costa Atlántica ${ }^{26}$, donde aludió a la necesidad de mantener las conquistas sociales ${ }^{27}$ y la unidad regional. Por otra parte, el dos de marzo el editorial de El Espectador destacó el número de habitantes de Bogotá y el potencial electoral que representaba, conformado por la clase media-trabajadora, para quien debía diseñarse nuevas técnicas de acción, motivación y propaganda en la campaña electoral ${ }^{28}$. Mientras El Espectador y El Tiempo hablaban de las grandes manifestaciones de Pastrana en la Costa, El Siglo en titular de prensa publicó: "Desconcierto por el fracaso de Pastrana", al referirse a las manifestaciones en esta región. Según este diario, el candidato regresó a la capital de la república después de una gira por Córdoba, Sucre y Bolívar, donde no encontró apoyo para su aspiración presidencial; señaló que "[...] la gira de Pastrana registró el más estruendoso fracaso en las tres comarcas, y estuvo rodeada de numerosos sucesos, ya que las contramanifestaciones eran tres y cuatro veces superiores a los actos preparados en su honor" ${ }^{29}$. Al parecer, en estos tres departamentos el candidato no contaba con dirigentes ni apoyo popular.

Después de la visita a las localidades de la Costa, Pastrana se dirigió a Antioquia, Ibagué y a otras regiones del país ${ }^{30}$, entretanto, en Bogotá el alcalde Virgilio Barco reforzaba la acción proselitista, que era publicada por la prensa ${ }^{31}$. Asimismo, se destacaron las obras inauguradas durante la administración Lleras, y la acción del Frente Nacional en general, como argumento electoral a favor del continuismo. Simultáneamente, se debatía sobre la situación, el cierre de las universidades Nacional y del Quindío, y las frecuentes marchas de estudiantes y profesores en defensa de la educación pública.

Como parte de la campaña electoral pastranista, las intervenciones del presidente Carlos Lleras Restrepo fueron frecuentes. El 8 de marzo El Espectador tituló: "Seré imparcial pero no en el debate electoral", en alusión a una intervención del presidente en la que hizo una fuerte defensa del Frente Nacional, destacó las obras públicas adelantadas durante su gobierno e invitó al electorado a votar por la continuidad del acuerdo político. Lleras señaló: "Rojas Pinilla no triunfará" e invitó a votar por el Frente Nacional ${ }^{32}$. En la localidad de Kennedy, en Bogotá,

\footnotetext{
${ }^{26}$ El Espectador, 1 de marzo de 1970.

27 "No habrá retroceso en las conquistas sociales", en El Espectador, 2 de marzo de 1970; "12 discursos de Pastrana el domingo, en gira por la costa", en El Espectador, 3 de marzo de 1970,

28 "La contribución de Bogotá a la victoria", en El Espectador, 2 de marzo de 1970.

${ }^{29}$ El Siglo, 4 de marzo de 1970.

${ }^{30}$ El Espectador, 8 de marzo de 1970.

31 "Pastrana logrará la acción", en El Espectador, Bogotá, 5 de marzo de 1970; El Espectador, Bogotá, el 6 de marzo de 1970.

${ }^{32}$ El Espectador, 9 de marzo de 1970.
} 
el Presidente hizo mención de las obras realizadas en los 12 años de vigencia del Frente Nacional, también contrapuso el debate público entre el gobierno "democrático" y la "dictadura", le preguntó al público cuál representaría mayores beneficios para el pueblo colombiano. De esta manera, Lleras inició una intensa campaña de visita a los barrios y sectores populares, especialmente en Bogotá, para destacar la importancia de la continuidad. Dentro las temáticas, abordó el debate electoral y las elecciones, la problemática universitaria, los avances de la educación, las obras públicas, el deber de votar libremente; a su vez, se refirió a las garantías democráticas y a la demagogia de los candidatos. En su discurso hizo alusión a la violencia generada durante el gobierno de Rojas, particularmente a la muerte de liberales en la Casa Liberal de Cali, a la consolidación de los pájaros y cóndores en el Valle del Cauca, a la censura a periódicos y emisoras, concluyó su disertación invitando a los adultos a sufragar por el Frente Nacional, que denominó la continuidad de la democracia. Continuó El Espectador en sus primeras páginas con mensajes como: "Votar contra nueva dictadura pide Alberto Lleras"; "no es lo mismo votar porque una democracia continúe, que votar para que se restaure una dictadura que no se ha arrepentido de nada de lo que hizo"33, en estos titulares el nombre de Lleras Restrepo como presidente fue una constante y se utilizó para convocar al electorado en la continuidad del Frente Nacional.

Mientras Lleras reitera la importancia del Frente Nacional, Pastrana continúa las correrías por las diversas localidades, entre estas, Tunja, Sogamoso y Duitama ${ }^{34}$. El Espectador hizo referencia a la gran 'manifestación' que se había realizado en Tunja, pero El Siglo señaló que la 'manifestación' se realizó con poca asistencia y poca convocatoria del candidato, sumado a esto presentó una fotografía que controvierte la versión publicada por El Espectador ${ }^{35}$.

Posteriormente, se hizo mención a la visita de Pastrana a Antioquia, la presentación de Rojas en Medellín, las manifestaciones de ambos candidatos y las multitudinarias adhesiones $^{36}$. Hacia el 25 de marzo, El Siglo presentó una fuerte crítica a la forma como el oficialismo descaradamente apoyó la candidatura de Pastrana; expone la imagen propagandística del candidato Pastrana, en cuyo fondo se encuentran las fotos del alcalde de Bogotá, Virgilio Barco y el presidente Lleras; cuestiona la forma como la candidatura de Pastrana está siempre respaldada por el alcalde de Bogotá y por el presidente de la República, lo que hace plantear una pregunta: “¿está de acuerdo el presidente Lleras en que se utilice su efigie para fines electorales, o este recurso hace parte de la 'neutralidad' oficial?" 37 .

\footnotetext{
${ }^{33}$ El espectador, 12 de marzo de 1970; "Pastrana es la antítesis de la dictadura": Alberto Lleras, en El espectador, 16 de marzo de 1970.

${ }^{34}$ El Espectador, 14 de marzo de 1970.

${ }^{35}$ El Siglo, 15 de marzo de 1970.

${ }^{36}$ El Espectador, 19 de marzo de 1970, p. 1-7.

${ }^{37}$ El Siglo, 25 de marzo de 1970.
} 


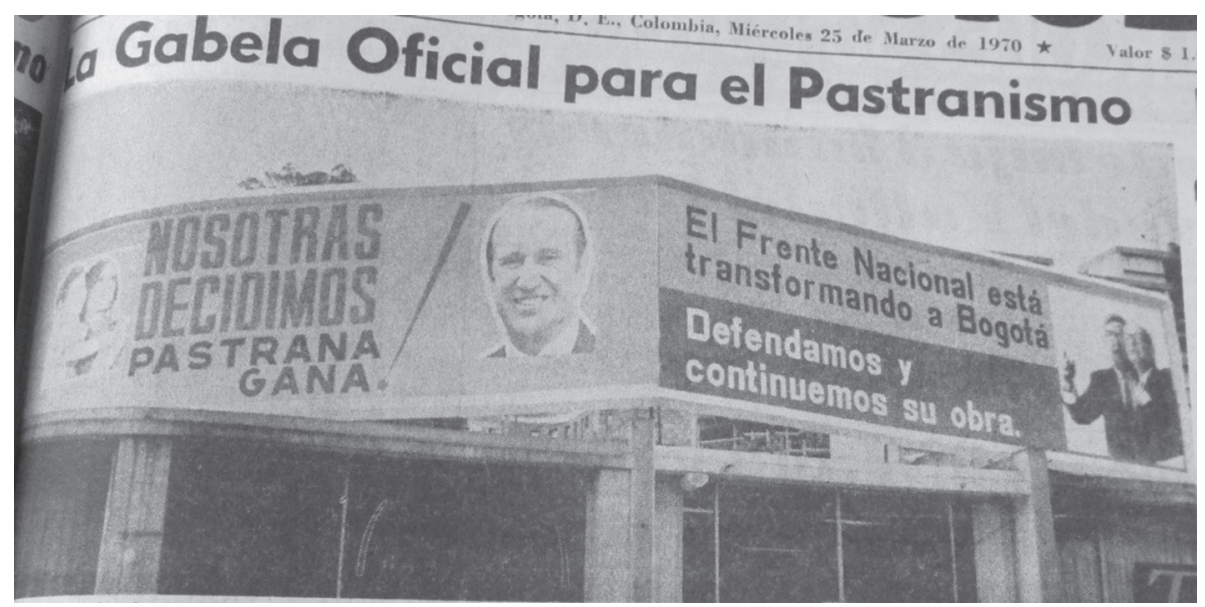

Fuente: El Siglo, Bogotá, 25 de marzo de 1970.

A partir de abril se intensificó la campaña electoral y creció el fervor político, los periódicos El Espectador, El Tiempo y Vanguardia Liberal realizaron una intensa campaña de desprestigio de la labor de Rojas Pinilla como presidente (1953-1957), aludiendo a la dictadura con todas sus implicaciones y contraponiéndola a la democracia planteada por medio del Frente Nacional ${ }^{38}$.

Abiertamente señalaron que Rojas era una amenaza para los partidos y para las libertades, en particular la de expresión; se centraron en recordar las situaciones más críticas de su mandato, especialmente los atentados contra los estudiantes el 8 y 9 de junio de $1954^{39}$, a la vez que hacían fuertes críticas sobre el desarrollo de las finanzas y la política fiscal implementada durante el gobierno del General, entre estas: asesinatos y persecución política, censura de radio y prensa, inflación y desconocimiento de una política económica.

Por su parte, Vanguardia Liberal publicó:

Las delicias de la dictadura.

Equipos de sonido ensordecen el ambiente bumangués, invitando a la ciudadanía a atribuir caluroso recibimiento al dictador Gustavo Rojas Pinilla, anciano que cuando ocupó la primera magistratura no hizo nada por Santander.

Eso fue lo que oímos ayer en los corrillos. Porque [sic] tanta algarabía cuando llega acompañado de su yernísimo personaje muy estimado, en Enciso donde todavía huele a incendio, cuando las gentes de este departamento no tienen nada que agradecerles, fuera de "hazañas" de muy ingrata recordación.

Pero la amnésica memoria de algunos hace olvidar estas pequeñas demostraciones de poder, que si no ha sido por legendarios hombres del partido

\footnotetext{
38 "Agonizó la marcha de la dictadura sobre el poder", "Pastrana en barrios de Bogotá" en Vanguardia Liberal, Bucaramanga, 2 de abril de 1970.

${ }^{39}$ El Espectador, 4 de abril de 1970; El Tiempo, 5 de abril de 1970; El Espectador, 10,11 de abril de 1970; "las delicias de la dictadura" en Vanguardia Liberal, 9 de abril de 1970.
} 
como Rafael Rangel Gómez, Helio Luque y otros más, este departamento sería ahora de propiedad exclusiva de los hermanos godos ${ }^{40}$.

Los periódicos, en el seguimiento a la campaña electoral, informaron sobre las diversas actividades del candidato frentenacionalista, visitas, correrías, desfiles, discursos, entre otros ${ }^{41}$. Pastrana fue presentado como el salvador de la patria, frente al dictador, por eso se pudo apreciar que un buen número de artículos, titulares y fotografías tenían esta intencionalidad. En forma jocosa se usaron las caricaturas, que a la vez tenían mensajes subliminales para el elector. En las siguientes caricaturas se puede apreciar la representación del debate electoral.

Imagen 1

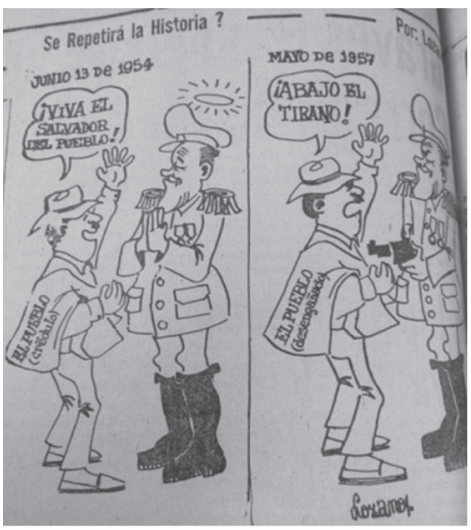

Imagen 2

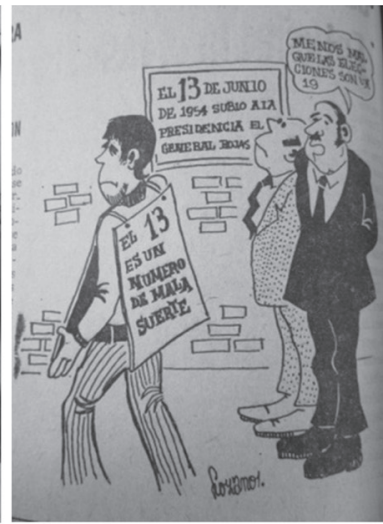

Imagen 3

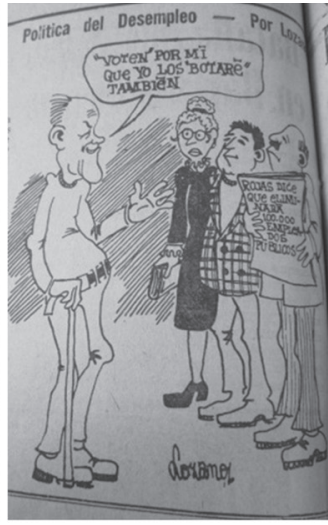

Fuente: Vanguardia Liberal, Bucaramanga, 10, 11 y 13 de abril de 1970.

En las caricaturas, Rojas es presentado como manipulador, traidor y tirano; en la primera se representa al pueblo victimizado frente a la acción de Rojas como dictador, quien lo agrede después de haberlo utilizado y con su sonrisa cínica justifica la tiranía; en la segunda, se retoma como representación el número 13, día en que llegó Rojas a la presidencia, con este dato se pretende recordar que ese día se instauró la dictadura en el poder y que por lo tanto podría ser una fecha que trae mala suerte; en la número tres se deja un mensaje sobre la representación del empleo con el uso de palabras homónimas como votar y botar, que tienen representaciones distintas y caracterizan acciones distintas, igualmente aparece la representación de la expresión sarcástica en el rostro del candidato.

\footnotetext{
${ }^{40}$ Vanguardia Liberal, 9 de abril de 1970.

41 "Rechazo a la dictadura, el sectarismo y la violencia; pidió Pastrana Borrero en Caquetá" en El Espectador, 10 de abril, 1970; El Colombiano, 10 de abril de 1970; "La oposición fracasará en las urnas" en Vanguardia Liberal, 10 de abril de 1970; "A las 8:30 hablará Pastrana por la T.V” en El País, Cali, 12 abril de 1970; "Misael Pastrana Borrero es la salvación de Colombia, afirmó Lleras Camargo* Rojas, el comienzo del desbarajuste", El País, Cali, 13 de abril de 1970; El Espectador, 13 de abril de 1970; "Belisario es el único candidato que conoció las cárceles de Rojas. Su voto por Belisario contribuirá a la victoria de la democracia" en El Espectador, 14 de abril de 1970.
} 
Las fuertes críticas a la dictadura y a las políticas asumidas por Rojas Pinilla fueron frecuentes, con estas se pretendió recordar colectivamente el significado político de la administración Rojas-dictadura; frecuentemente se usaron los apelativos de asesino, pájaro y dictador para referirse al expresidente. Unos de los sucesos que más aparecieron fueron los hechos del 8 y 9 de junio, el asesinato del estudiante Uriel Gutiérrez, la caída de Rojas y la censura de prensa, con fotografías como la que aparece a continuación:

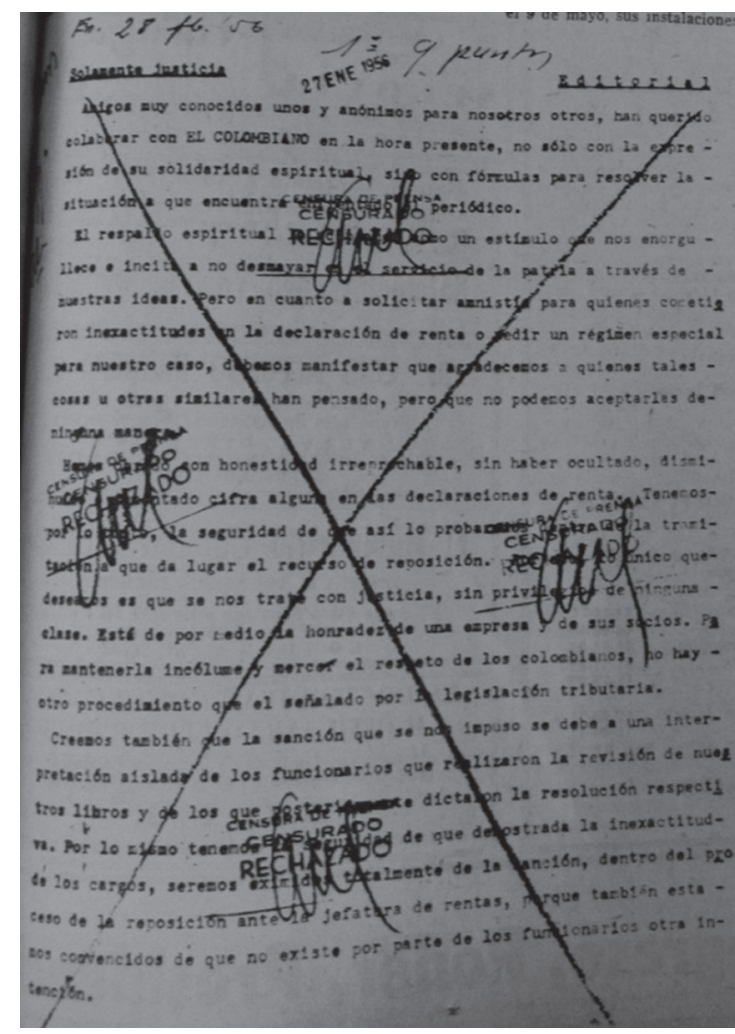

Fuente: El Colombiano, Medellín, 18 de abril de 1970.

En este documento podemos apreciar la censura que tuvieron los medios; el comité censor del gobierno aprobaba o no la publicación o tachaba fragmentos. Con la publicación de estas imágenes se pretendió justificar la elección de Misael Pastrana, que al parecer garantizaría las libertades, en contradicción a la acción de Rojas Pinilla que en su periodo presidencial (1953-1957) había censurado la prensa y había establecido prácticas de persecución y exclusión. La prensa pretendió dejar en los electores la sensación de que la democracia solamente se lograba con el triunfo de Pastrana, ¿pero qué tanto recordaron los electores estos hechos a la hora de emitir su voto?

En la memoria de muchos habitantes permanecía la imagen de Rojas como organizador de los pájaros en el Valle del Cauca, en la década de los cincuenta, con el fín de "controlar" la situación de orden público. En oficio enviado al presidente Lleras, el 
señor Pedro Vicente López, habitante de Bucaramanga, expresó su preocupación por las versiones de radio y prensa escrita que señalaban sobre la manifestación efectuada el sábado anterior en la plaza de Bolívar:

[...] [el] ignominioso pájaro, tirano exdictador Rojas Pinilla, fue lo más impresionante que se haya visto en nuestra capital [...] Lo cual nos hace suponer que nuestro Partido Liberal está próximo al fracaso!!! Pero en todo caso es de lógica que quienes asistieron fue la cúpula y lo más bajo que tiene nuestra urbe ${ }^{42}$.

De esta manera se minimizó el papel político de los sectores populares, mientras la convocatoria y el programa de gobierno habían transformado su perspectiva electoral.

\section{Votos y electores: ¿legitimidad o fraude?}

En este apartado nos centramos en analizar los datos electorales por departamento, de acuerdo con la información oficial transmitida a través de los medios de comunicación que oscilaron entre el triunfo, la derrota, el fraude y el uso de la información para influir en la memoria colectiva. De esta manera es importante hacer seguimiento a la publicación de los resultados electorales que dieron la sensación de triunfo y fraude en el debate electoral, principalmente en las elecciones presidenciales.

El 19 de abril se llevaron a cabo las elecciones presidenciales y para corporaciones públicas; la mayoría de periódicos coincidieron en señalar que el debate se había realizado en orden, en calma y con gran espíritu cívico. Por ende, el inconveniente no estuvo en la emisión del sufragio, sino en la etapa del conteo y reconteo de votos que mantuvieron en zozobra a candidatos y seguidores. Los escrutinios se iniciaron inmediatamente se cerraron las mesas de votación, aunque fue dispendioso por el número de candidatos a las diversas corporaciones, el punto nodal estaba en la elección presidencial. Así las cosas, a medida que se escrutaba un número de mesas, la Registraduría hacía un consolidado y emitía un boletín oficial que era transmitido en las emisoras.

A la media noche del 19 de abril, se generaron ambivalencias en la presentación de los resultados electorales, lo que causó fuertes confusiones en los medios de comunicación y en los electores, que dieron pie a la emisión de versiones diferentes sobre una misma situación. Estas versiones, al mismo tiempo, se entrecruzaron y crearon polémicas entre el gobierno y los medios, puesto que los electores recibieron comunicaciones que ponían en duda el triunfo de los candidatos o sugerían el fraude en el conteo de los votos. El ministro de Gobierno, Carlos Augusto Noriega, desmintió la información emitida por la radio y cuestionó cualquier tipo de información diferente a la "oficial"; pidió a las emisoras no hacer "telenovela electoral" y desautorizó las cifras que habían transmitido las emisoras, las consideró improvisadas y no oficiales ${ }^{43}$.

\footnotetext{
${ }^{42}$ AGN, despacho del Sr. Presidente, secretaría privada, partidos políticos, correspondencia, 1970, caja No. 109, carpeta 1, f. 44. Oficio enviado al Presidente Carlos Lleras Restrepo, de la empresa de transportes Copetrán de Bucaramanga, 7 de abril de 1970, firmado Pedro Jacinto López.

${ }^{43}$ El Siglo, 20 de abril de 1970.
} 
El 20 de abril, al otro día del debate electoral, los reportajes periodísticos aún eran ambivalentes. Según los datos de la Registraduría, Misael Pastrana tenía una pequeña mayoría. Pero, según los reportajes emitidos por las emisoras antes de la media noche del 19, el ganador era Gustavo Rojas Pinilla y hasta él mismo llegó a creerlo así, en una intervención radial prometió hacer un gobierno de paz, justicia y libertad.

La ambivalencia se pudo apreciar en las primeras páginas de los periódicos, que presentaron al ganador desde ópticas distintas: El Siglo publicó: "Rojas a la cabecera en cómputos electorales. Amplía su mayoría en centros urbanos", con lo cual le daba el triunfo a Gustavo Rojas Pinilla, aludiendo a los resultados emitidos a las once de la noche; El Espectador, expresando indecisión, publicó los datos oficiales emitidos a las 3:00 a.m., según los cuales Pastrana Borrero tenía 1368 981, mientras que Rojas Pinilla tenía $1366364^{44}$. A continuación se relacionan los resultados electorales antes de la medianoche:

Resultados electorales a la medianoche del 19 de abril de 1970

\begin{tabular}{|l|c|c|c|}
\hline Candidato presidencial & $\begin{array}{c}\text { Resultados 10:30 } \\
\text { p.m. }\end{array}$ & $\begin{array}{c}\text { Resultados 11:45 } \\
\text { p.m. }\end{array}$ & $\begin{array}{c}\text { Resultados 1:30 } \\
\text { a.m. }\end{array}$ \\
\hline Belisario Betancur & 229.338 & 353.697 & 437.218 \\
\hline Misael Pastrana & 744.022 & 1.096 .140 & 1.396 .695 \\
\hline Gustavo Rojas Pinilla & 753.243 & 1.117 .902 & 1.429 .325 \\
\hline Evaristo Sourdís & 95.506 & 157.458 & 156.544 \\
\hline
\end{tabular}

Fuente: Elaborado a partir de la información de: El Siglo, 20 de abril de 1970 (11:45p.m.); El País, 20 de abril de 1970 (boletín de prensa de las 12:00 p.m.); La Patria, 20 de abril de 1970 (boletín de la Registraduría 1:30 a.m.); El Espectador (12:00 p.m.).

Los periódicos coinciden en que en 1970 hubo un incremento del número de sufragios con relación a los comicios de 1966; señalan que el debate había estado reñido y que, según los boletines de la Registraduría emitidos hasta la medianoche, Gustavo Rojas Pinilla era el ganador. El periódico El País, según el boletín de las 12:00 p.m. -que al parecer contenía los datos de 920 municipios- coincide con los resultados publicados por El Siglo y El Espectador del 20 de abril, en que Gustavo Rojas Pinilla tenía las mayorías.

El periódico El Colombiano, también dudó al publicar los resultados electorales; en un titular de prensa expuso: "Pastrana-Rojas: Una incógnita. Pastrana 1.373.424 - Rojas 1.367.671. Resultados extraoficiales" ${ }^{45}$. Por su parte, el periódico Vanguardia Liberal hizo alusión al boletín publicado por la Registraduría a las once de la noche; señaló que las mayorías hasta ese momento las tenía el candidato Rojas Pinilla, de igual forma, reiteró la alocución del Ministro de Gobierno ${ }^{46}$, con relación a la información transmitida por las emisoras.

\footnotetext{
${ }^{44}$ El Espectador, 20 de abril de 1970.

${ }^{45}$ El Colombiano, Medellín, 20 de abril de 1970.

46 "Así votaron los colombianos" (Registraduría Nacional a las 11:00 p.m.) en Vanguardia Liberal, 20 de abril de 1970; "Min. Gobierno desmiente los datos electorales de radio" en El Heraldo, 20 de abril de 1970.
} 
Es de destacar que con base en los datos antes señalados se dio por ganador de los comicios a Rojas Pinilla, puesto que, aparentemente, los escrutinios eran el consolidado de la mayoría de las mesas de votación. Con posterioridad a estos datos y a la intervención del ministro se hizo mención de fallas en la energía y en las líneas telegráficas y telefónicas en varias regiones del país.

El 21 de abril ya ningún medio dudaba del número de votos que beneficiaban a Pastrana, a pesar del recuerdo de los habitantes sobre las mayorías que llevaba Rojas Pinilla, según los boletines de la Registraduría. Los titulares de prensa coincidieron en que Pastrana tenía mayorías; el periódico El País publicó: "Mayoría definitiva por Pastrana 1.493.630 votos a su favor frente a 1.471.140 de Rojas" "47; se indicó una ventaja de 22490 votos, del mismo modo con los votos obtenidos en el extranjero. Estos datos fueron tomados del boletín oficial de la Registraduría publicado el 20 de abril a las 8:45 pm., equivalente al 96\% de las mesas. Por otra parte, Belisario Betancur había obtenido 442011 votos, mientras Evaristo Sourdís, 250233 votos.

Los titulares de prensa del 22 de abril ya se referían a los 66018 votos de ventaja que obtuvo Pastrana ${ }^{48}$; sin embargo, ¿cómo se legitimó ese triunfo?, ¿qué piensan los habitantes sobre el número de sufragios que intempestivamente favorecieron a Pastrana? y ¿de qué manera se evitó que las manifestaciones tomaran un tinte de revuelta para tomarse el poder? Son los interrogantes que a continuación se esperan ver resueltos, pero ello no ocurre.

\section{El uso del poder en los resultados electorales}

En tanto que los periódicos reiteraban el triunfo de Pastrana, la población reclamaba justicia, revisión de los datos y respeto a la voluntad popular. El diario El Siglo, de tendencia conservadora publicó:

Los imprecisos datos electorales de ayer y el margen de ventaja del candidato Misael Pastrana Borrero que comenzó a descontárselos al General Rojas Pinilla a partir de la madrugada del lunes, provocaron la reacción de los anapistas, que efectuaron ayer varios mítines que fueron disueltos por las tropas regulares ${ }^{49}$.

Aunque los grupos anapistas permanecieron en las calles con la pretensión de continuar con la manifestación, reclamando justicia y honestidad en el conteo de los votos, la policía utilizó todas las medidas para disolver a los manifestantes, mediante el despliegue de tropas, tanquetas, jeeps y vehículos ubicados en distintos lugares de la ciudad, especialmente en el Parque de los Periodistas. Así mismo, hubo manifestaciones en Barranquilla, donde los anapistas se reunieron cerca de

\footnotetext{
${ }^{47}$ El País, 21 de abril de 1970; El Siglo, 21 de abril de 1970; Vanguardia Liberal, 21 de abril de 1970; La Patria, 21 de abril de 1970; El Heraldo, 21 de abril de 1970; "Pastrana 1.493.630 - Rojas 1.471.140" en El Espectador, 21 de abril de 1970; El Siglo, 21 de abril de 1970; La Patria, 21 de abril de 1970.

${ }^{48}$ El Colombiano, 21 de abril de 1970, "Se consolida triunfo a Pastrana. Se contabiliza mayoría de 66.000 votos sobre Gustavo Rojas Pinilla”; El País, 24 de abril de 1970.

49 "Emergencia militar en la capital”, "Tensión en varias ciudades del país”, en El Siglo, 21 de abril de 1970.
} 
la gobernación del Atlántico y desfilaron por las principales calles reclamando a la Registraduría por justicia, pues consideraban que los resultados habían descendido en más de 100.000 votos. Por su parte, El Heraldo hizo alusión a manifestaciones en varias regiones del país ${ }^{50}$.

La expectativa de los inciertos registros electorales generó tensiones que llevaron a una serie de protestas-mítines, por parte de los electores que se sintieron defraudados, estas fueron controladas con gases lacrimógenos. El 21 de abril las manifestaciones realizadas en el centro de Bogotá estuvieron bastante agitadas; allí desfilaron hombres y mujeres con ruanas y banderas de color azul, blanco y rojo, los colores de la Alianza Nacional Popular. Las gentes gritaban: "el pueblo reclama el triunfo de Rojas" y "[...] no permitamos un nuevo engaño", mientras recorrían las calles con las manos en alto, haciendo la "V" de la victoria ${ }^{51}$. El fervor crecía, los manifestantes gritaban "viva la revolución" y se negaron a desocupar las vías céntricas de la capital. Horas más tarde fueron apedreados los periódicos El Tiempo y La República; almacenes, droguerías, restaurantes y hoteles fueron saqueados ${ }^{52}$. Las operaciones del ejército y la policía fueron respondidas agresivamente por los manifestantes, que trataron de hacer barricadas, pero intervino la caballería para disolver la manifestación ${ }^{53}$.

Finalmente, la medida del gobierno para controvertir estos hechos fue declarar "estado de sitio" en todo el territorio nacional, toque de queda en algunas localidades y censura de prensa $^{54}$; el gobierno señaló que clausuraría cualquier periódico o emisora que incumpliera la norma.

Para acallar las manifestaciones se ordenó la detención de los principales líderes anapistas, sindicados por el gobierno de haber pretendido crear un alzamiento general para derrocar a las autoridades. A su vez, Rojas Pinilla fue retenido en su casa, bajo control militar ${ }^{55}$. Esta fue una medida del gobierno para controlar las acciones de Rojas Pinilla y evitar cualquier tipo de levantamiento popular, pues si controlaban a los líderes y a los medios de comunicación era muy difícil que las masas lograran organizarse y levantarse contra el gobierno.

Además de las manifestaciones de los anapistas, hubo fuertes denuncias sobre fraude e irregularidades en el conteo de los votos en varias regiones, como la siguiente:

\footnotetext{
50 "Manifestación de Anapo en protesta por los resultados. Movilización rojista en todo el país", El Heraldo, 21 de abril de 1970 .

${ }^{51}$ CARDOZO, Alfonso, "Desorden en Bogotá," Vanguardia liberal, 21 de abril de 1970.

52 "La derrota fue para la camarilla política. El pueblo se rebeló contra maniobras que se tejieron para imponer a Pastrana", en El siglo, 21 de abril de 1970.

${ }_{53}$ Civiles y uniformados rodaron por el suelo. Numerosos contusos arrojó el encuentro. Un PM fue derribado de su cabalgadura y recogido por sus compañeros. Otro oficial recibió el impacto de un objeto que le arrojaron y cayó al suelo. Dos más fueron heridos a piedra. "Serios choques ayer en Bogotá", en $E l$ Tiempo, 22 de abril de 1970.

54 "Decretado estado de sitio anoche. Toque de queda, censura a prensa y radio", en El Siglo, 22 de abril de 1970; El País, 22 de abril de 1970; La Patria, 22 de abril de 1970; Vanguardia Liberal, 23 de abril de 1970.

${ }^{55}$ El Siglo, de 23 de abril de 1970.
} 
Siendo yo jurado en una de las mesas de votación en el pueblo Cundinamarqués, y que lógicamente se deseaba saber quién sería el vencedor y quiénes los vencidos; pues bien allí ganó a quien usted Sr. Presidente amparara y dio garantías para el abuso, Sr. Misael Pastrana; victoria sobrada sobre los otros candidatos, pero como vieron era uno de los tantos pueblos que corría a la burla enturbiado por el dinero y pareciéndoles poco el triunfo necesitaron poner en el juego mágico de los números el aumento descarado de 1154 a 1554 votos; esto sucedió allí donde ganó, pueblo pequeño y fácil de controlar. Se diría usted Sr. Presidente de aquellas ciudades donde fue difícil el control y el pueblo no colaboró con su corriente? [sic] $]^{56}$

Tal parece, en muchas mesas de votación hubo “confusión” en el conteo de los votos, en otras se responsabilizó a los sistemas de comunicación y en otras, intempestivamente, aparecieron votos del candidato oficialista. Por eso el 21 de abril, dos días después de los comicios, se corrigieron los datos emitidos en los departamentos de Sucre, Quindío y Tolima, de acuerdo con lo trasmitido en el boletín No. 5 de la Registraduría ${ }^{57}$. La prensa no dio mayores detalles sobre el particular. Al contrastar la información con la que debería existir en la Registraduría, nos encontramos con que no existe un archivo en que se pueda tener acceso a los boletines de prensa, a la correspondencia y a las reclamaciones; lo único existente es la publicación de las estadísticas electorales, que para un historiador es solamente un indicio.

También hubo denuncias de la localidad de Rovira (Tolima), cuyo alcalde fue el encargado de guardar las tres llaves que contenían los documentos del proceso electoral, las que debían quedar en poder de 3 personas diferentes; se denuncia que la urna fue encontrada con los sellos rotos y no hubo explicaciones del alcalde sobre el particular $^{58}$.

Por otra parte, se denunció fraude en Putumayo, donde el número de votos superó el número de cédulas inscritas, considerado "el 'chocorazo' más descarado [...]". En esta región el número de cédulas inscritas era de 23 000, no obstante, según los datos contenidos en el boletín No. 4 de la Registraduría, la votación del Putumayo fue de 24.933 sufragios, es decir, 1933 votos más que el número de cédulas vigentes. Según los comicios anteriores, el promedio de votos obtenidos había sido de 5000 , así que el resultado de estos comicios era cinco veces superior ${ }^{59}$.

Igualmente, se denunció fraude en Arauca, allí se señaló que se produjo un descenso de los votos de Rojas Pinilla de 2823 a 2 383, mientras que por Pastrana subió el número de 2424 a $3096^{60}$. De modo similar ocurrió en Nariño, donde las denuncias exponían que el número de papeletas no coincidía con el número de votantes inscritos, otros

\footnotetext{
${ }^{56}$ AGN, Presidencia de la República, Oficio enviado al presidente Carlos Lleras Restrepo por GASARURE, Bogotá, abril 21 de 1970.

${ }^{57}$ El Espectador, 21 de abril de 1970.

58 "Las tres llaves de la urna se guardó el alcalde", en El Siglo, 28 de abril de 1970.

59 "Fraude en Putumayo. La votación excedió número de cédulas escritas", en El Siglo, 29 de abril de 1970.

60 "Investigan fraude. El comité revisa elección del Putumayo", en El Siglo, 1 de mayo de 1970.
} 
pliegos no llevaban la firma del registrador, en general se produjeron irregularidades en los comicios efectuados en este departamento; "en sacos de azúcar llevaron en Nariño votos fraudulentos". Asimismo, en el departamento de Magdalena se hizo alusión a que había electores que aparecían sufragando sin que sus cédulas se hubieran inscrito; mientras que en Risaralda se pudo apreciar la votación de personas fallecidas, los presos comunes, funcionarios del resguardo y otros empleados que por razones de su posición se encontraban impedidos para sufragar ${ }^{61}$. En algunas localidades, especialmente en las inspecciones de policía, se encontró doble cedulación, tránsito libre intermunicipal y más votos que votantes en muchos municipios. En algunas veredas se presentaron urnas abiertas y paquetes sin lacrar, por lo que se sospecha que después de la implementación del toque de queda, funcionarios incrementaron el número de votos; se concluye que a altas horas de la noche fueron alterados y adulterados los resultados de las elecciones. También se pudo apreciar compra de votos.

En Floridablanca y Bucaramanga se denunció doble votación, votos con cédulas de personas fallecidas y votos de personas que no tenían derecho a sufragar. En localidades como Villa de Caro, además de fraude, hubo coacción a los simpatizantes de la ANAPO, y papeletas sin doblar (399); mientras que de Pamplonita denunciaron que se cambiaron votos de Rojas Pinilla en favor del oficialista Pastrana Borrero ${ }^{62}$.

Como se señaló, para mediar la situación de orden público el gobierno ordenó la detención de los líderes del anapismo, entre ellos Ignacio Vives, cuyos discursos fueron catalogados como subversivos; al respecto, se encuentran varios documentos en los que se denuncia la persecución a la ANAPO y se solicita al presidente de la República la liberación de los líderes políticos ${ }^{63}$. Esta liberación se solicitó teniendo en cuenta que habían transcurrido más de 10 días desde la captura y no se había seguido el debido proceso, lo que configuraba una arbitrariedad. Por otra parte, protestaban contra el allanamiento de oficinas políticas y sindicales, detención arbitraria a dirigentes del partido, sindicalistas y dirigentes sindicales ${ }^{64}$.

De diversas regiones del país llegaron mensajes tanto al presidente como al Ministro Noriega, demandando que se respetara la voluntad del pueblo ${ }^{65}$. En un comunicado

\footnotetext{
${ }^{61}$ El Siglo, 8 de mayo de 1970.

${ }^{62}$ El Siglo, 8 de mayo de 1970.

${ }^{63}$ AGN, Fondo presidencia la República, despacho del Sr. Presidente, partidos políticos, correspondencia, caja No. 185, carpeta 1, ff. 1-50, 1970. Oficio firmado por Oscar Antonio Osorio dirigido al Presidente Carlos 1leras Restrepo, Bogotá, julio 1 de 1970, f. 119. AGN, Fondo Despacho del señor Presidente, partidos políticos, correspondencia, caja No. 185, carpeta 1, f. 1- 50, 1970. Oficio enviado al Presidente Carlos Lleras Restrepo, abril 30 de 1970, f. 5, firmado por Gustavo Rojas Pinilla de la Alianza Nacional Popular-Comité Ejecutivo, abril 30 de 1970, f. 5.

${ }^{64}$ AGN, Fondo presidencia la República, despacho del Sr. Presidente, Oficio enviado por algunos ciudadanos al Presidente Carlos lleras Restrepo, Medellín, 5 de mayo de 1970, f. 65.

${ }^{65}$ AGN, Despacho del Señor Presidente, oficio enviado por las mujeres de Medellín al Presidente de la República, Carlos Lleras Restrepo, folio 79, mayo de 1970, recepcionado el 19 de mayo. AGN, Oficio enviado por René García Lizarralde, presbítero, al presidente Misael Pastrana Borrero, Bogotá, agosto 10 de 1970, ff.168- 178. AGN, presidencia la República, despacho del Sr. Presidente, partidos políticos,
} 
de las mujeres de Medellín se denunció la estrategia para burlarle la buena fe a los millones de colombianos, porque para ellas el ganador era Gustavo Rojas Pinilla, se preguntaban ¿por qué engañar al pueblo? En la conciencia popular, especialmente, quedó marcado el fraude electoral.

\section{Conclusiones}

La elección presidencial de 1970 tuvo características muy importantes, porque permitió la apertura electoral, al retornar aspectos significativos de la democracia como la elección directa de Concejos y Asambleas y que el triunfo se tomara de acuerdo con las mayorías y no con la rotación partidista liberal-conservadora. En otro sentido, los actores sociales tuvieron la posibilidad de elegir a uno de los cuatro candidatos que se presentaron con propuestas de gobierno diferentes, de esta manera los colombianos experimentaron el retorno a la democracia, porque de una u otra forma asumieron un papel político al seguir al candidato que les ofrecía mejores beneficios y que para ellos representaba un cambio.

Los cuatro candidatos desplegaron actividades electorales que les permitieron acercarse a los electores, las mayorías se encontraban en los sectores populares y a la vez eran los grupos más vulnerables, que se veían afectados por el alto costo de vida, la pobreza y el hambre. Estos candidatos diseñaron estrategias para acercarse a los sectores populares y ganarse el respaldo, pero esta vez no fue suficiente la presencia del candidato, sino el contenido de su programa de gobierno, por lo que Rojas Pinilla, con sus pretensiones de bajar el costo de vida y mejorar las condiciones de los sectores más vulnerables, logró mayores seguidores, lo que se pudo apreciar en las manifestaciones que lo seguían. Por su parte, el representante de las elites liberales y conservadoras y del acuerdo bipartidista, Misael Pastrana Borrero, contó con el apoyo de líderes políticos de gran renombre, como Carlos Lleras Restrepo -presidente de la República- y de los periódicos de circulación nacional. Así, se adelantó una campaña de imagen que osciló entre los beneficios del acuerdo político frentenacionalista y los recuerdos de las elites sobre el periodo de gobierno del General Rojas Pinilla, conocido como "dictadura", en especial los abusos de poder por parte de las fuerzas militares; campaña que pretende incidir en la memoria del pueblo, para quien Rojas Pinilla era un héroe. Se consolidaron, entonces, dos tendencias antagónicas: los defensores de las elites y del acuerdo frentenacionalista y los defensores de los sectores populares o Alianza Nacional Popular, en cabeza de Gustavo Rojas Pinilla.

La prensa regional y nacional se centró básicamente en el manejo de los registros electorales, particularmente en lo concerniente al conteo y reconteo de los votos, donde los actores sociales no lograron comprender los cambios en las estadísticas electorales, el porqué de la corrección de los datos en ciertas localidades $\mathrm{y}$, sobre todo, la ambivalencia en la presentación de los datos. Muchos no comprendieron por

correspondencia, caja No. 185, carpeta 1, ff. 1-50, 1970. Comunicado número ocho, expedido por el General Gustavo Rojas Pinilla, sobre el memorándum enviado a los candidatos presidenciales. Carlos Restrepo, Presidente de la República. Abril 30 de 1970, f. 6. Oficio enviado por los comandos de la Alianza Nacional Popular, barrios del sur, Bogotá, mayo 2 de 1970, f.7, dirigido al presidente Carlos lleras Restrepo. 
qué el candidato Rojas Pinilla perdió las elecciones si a la media noche del 19 de abril, día en que se realizaron los comicios, los registros oficiales ya lo daban como ganador, tampoco comprendieron por qué el Ministro de Gobierno prohibió a las emisoras transmitir información electoral, ni por qué aparecieron datos electorales que beneficiaban a Misael Pastrana cuando Rojas punteaba como ganador. En consecuencia, los electores asocian las elecciones presidenciales de 1970 con un fraude irresuelto, pues no quedaron satisfechos con los datos oficiales, que para la mayoría de los electores significaron una acción de poder del gobierno y una burla al sistema democrático.

Para mediar el inconformismo de los electores, y como estrategias para controlar a las masas que se sintieron burladas y que consideraron que las elecciones habían sido una farsa más, el gobierno, de tendencia liberal, ordenó detener a ciertos líderes de la ANAPO y vigilar a Rojas Pinilla, declaró turbado el orden público e implantó el estado de sitio, al igual que la censura de prensa. Para muchos electores era más fácil alterar los resultados electorales para darle las mayorías al candidato Misael Pastrana Borrero, mantener controladas las multitudes y detener y vigilar al líder político de la oposición sin terminar con su vida, puesto que con ello se evitaba un levantamiento de masas en varias regiones del país y un posible derrocamiento del poder por parte de los sectores populares.

\section{Fuentes}

\section{Fuentes Primarias}

\section{Archivos}

Archivo General de la Nación (AGN)

\section{Documentos}

Oficio enviado al presidente Carlos Lleras Restrepo por GASARURE, Bogotá, abril 21 de 1970.

Oficio firmado por Oscar Antonio Osorio dirigido al Presidente Carlos lleras Restrepo, Bogotá, julio 1 de 1970, folio 119.

Oficio enviado por algunos ciudadanos al Presidente Carlos lleras Restrepo, Medellín, 5 de mayo de 1970, folio 65.

Oficio enviado por las mujeres de Medellín al Presidente de la República, Carlos Lleras Restrepo, folio 79, mayo de 1970, recepcionado el 19 de mayo.

Oficio enviado por René García Lizarralde, presbítero, al presidente Misael Pastrana Borrero, Bogotá, agosto 10 de 1970. Folios 168-178. 


\section{Publicaciones seriadas}

El Siglo, Bogotá, 1970.

El Heraldo, Barranquilla, 1970.

La Patria, Manizales, 1970.

El Espectador, Bogotá 1970.

El Tiempo, Bogotá, 1970.

El Colombiano, Medellín, 1970.

Vanguardia Liberal, Bucaramanga, 1970.

El País, Cali, 1970.

\section{Fuentes secundarias}

\section{Libros}

ACUÑA RODRÍGUEZ, Olga Yanet, Elecciones y Construcción de ciudadanía en Boyacá, durante la República Liberal 1930-1946, Tunja, Universidad Pedagógica y Tecnológica de Colombia, 2010.

GANTÚS, Fausta, Caricatura y poder político. Caricatura, censura y represión en la ciudad de México, 1876-1888, México, El Colegio de México, 2009.

GANTÚS, Fausta y SALMERÓN, Alicia, Prensa y Elecciones formas de hacer política en el México del siglo XIX, México, Instituto Mora, 2014.

GONZÁleZ MARÍN, Silvia, Prensa y Poder Politico, la elección presidencial de 1940 en la prensa mexicana, México, Editorial Siglo XXI, 2010.

\section{Capítulos de libros}

ACUÑA RODRÍGUEZ, Olga Yanet, "Elecciones presidenciales de 1949 en Boyacá", en GUERRERO, ACUÑA(Comp.), Para reescribir el Siglo XX, Medellín, La Carreta, 2011 .

\section{Artículos}

BUSHNELL, David, "Las elecciones en Colombia: S. XIX para bien o para mal, las elecciones han sido una característica nacional”, en Revista Credencial Historia, No. 50, Bogotá, 1994. 